\title{
Sound Objects and Sound Products: Standardizing a New Culture of Listening in the First Half of the Twentieth Century
}

\author{
By Alexandra Hui
}

\begin{abstract}
In this chapter I develop the psychological underpinnings of environmental music towards an understanding of how the goals of cognitive and behavioral psychologists contributed to a new kind of listening at the beginning of the twentieth century. I begin with an examination of nineteenth-century concerns about both the physical and psychological effects of music and fraught debate among experimental psychologists of the role of musical expertise in the laboratory. These concerns were, I argue, rooted in the assumption of a direct, corporeal connection between the generation and reception of music, usually bound within a single, individual body. In the twentieth century, new technology liberated the listener from a temporally- and geographically-bound experience of music. The Tone Tests, Re-Creation Recitals, and Mood Change "parties" of Thomas Edison and the psychologist Walter Bingham show that recording technology allowed for a normalization and standardization of listening not previously possible in the music halls and laboratories of the nineteenth century. Rather paradoxically, since it also made music more accessible to the individual listener, recorded music, mobilized by industrial psychologists and record companies alike, created a new sound experience actively designed for the lowest common denominator of mass listening. It also contributed to the cultivation of a new practice of mass listening. The new mass listening practice presents broader questions about the definition of music and its functional role - If the function of music is to be ignored, is it still music?
\end{abstract}

Keywords: Tone Test, Mood Change, Standardization of Listening, Walter Bingham, Edison Phonograph 


\section{Introduction}

If Christmas card angels offer any proof, utopian creatures are forever smiling. Moozak, the sound wall of paradise, never weeps. It is the honeyed antidote to hell on earth. Moozak starts out with the high motive of orchestrating paradise (it is often present in writings about utopias) but it always ends up as the embalming fluid of earthly boredom. (Schafer, 1977/1994: 96)

In this way Canadian composer R. Murray Schafer begins the discussion of background music in his famed 1977 work, The Soundscape. His combination of the herd animal's "moo" with the most identifiable brand of background music, $\mathrm{Mu}-$ zak, belies his opinion of the practice well before he accuses it of reducing "a sacred art to a slobber" (Schafer 1977/1994: 98). He explained that background music was consciously designed to not be listened to, an acoustic wall that masks characteristic soundscapes.

Before their visages were reduced to the peaceful but blank stares of the embalmed, the Christmas card angels smiled. Schafer generously allowed that the original intentions of background music's developers were utopian. Background music had a history. There was an origin story of this sound object, consciously designed to not be listened to, just as, I would argue, there was an origin story of the type of listening required to allow one to become embalmed by its sound.

This type of listening, "threshold listening," came into being in the twentieth century, co-developing with sound recording and replay technology. Threshold listening is not quite active but also not quite passive. While the threshold listeners are not necessarily consciously aware of the music all the time, they respond to it both emotionally and physically. Sound studies scholars, musicologists, and cultural historians have long maintained the binary of active and passive listening, of listening and hearing. Threshold listening operates between these binaries, and long-term, a better understanding of the origins of threshold listening will hopefully bridge these binaries or blow them away.

Academic scholarship in science studies, sound studies, and the history of science has recently begun to explore the interaction between the world of science and the world of music, with rich and fruitful results (Thompson, 2002; Pinch \& Bjisterveld 2003; Sterne 2003; Jackson 2006). Much of this scholarship has been devoted to the history of sound sensation, noise abatement, acoustic architecture, concert listening culture; the concept of soundscapes, generally speaking (Johnson 1995; Pinch \& Trocco 2002; Thompson 2002; Sterne 2003; Bjisterveld 2008). These works also share a common interest in the evolving listening practices of the individual and the public.

So as not to mislead, I should note that this essay is not about Muzak specifically but rather the intellectual and cultural conditions and processes that made Muzak possible. I begin with a brief discussion of nineteenth-century ideas that circulated among - and between - both scientists and musicians about listening and the physical and emotional responses listening could potentially elicit. I then 
examine the early twentieth-century efforts of psychologists working in coordination with the Phonograph Division of the Thomas Edison Company to turn sound objects into marketable sound products through the cultivation of a new kind of listening. I will focus on the work of psychologist Walter van Dyke Bingham to measure the motor effects of music. I will then turn to the Tone Tests, ReCreation Recitals, and Mood Change Tests organized by the Edison Company to promote the phonograph. These performances, I argue, were a concerted effort to train the public to receive the sounds of the instrument in a specific way. I close with a brief discussion of the long-term consequences of these efforts, the Mood Change Tests especially. I argue that the cultivation of threshold listening was achieved as the sound object was standardized and the subjective practice of listening was objectified.

\section{Correct Listening and its Bodily Consequences in the Nineteenth Century}

The sonic world of the early decades of the twentieth century was highly unstable. There were new tuning systems, new non-Western music, and new Western music deliberately departed from earlier aesthetics, simultaneously moving backwards, resurrecting older folk traditions and forwards towards complete atonality. Musical sounds proliferated. Listeners also proliferated. Musicologists and psychologists debated their typologies and how to classify them (Myers 1927; Ortmann 1927). This discussion had its origins in the previous century. In both the music and natural science worlds there was an increase in the belief that there was a right and wrong way to listen. Related was a growing curiosity in the bodily effects of listening, the consequences of, say, listening incorrectly.

Within the scientific world, the study of sound sensation was splintering along the lines of the new disciplines and sub-disciplines. The new field of experimental psychology was increasingly interested in large aggregates of data collected from several experimental subjects of objectively measurable phenomena such as tone differentiation. This was in contrast to earlier practices of employing musicallytrained experimental subjects that mobilized their subjective experiences of sound to study such phenomena as accommodation, undertones, duplex tones. This use of musical expertise as scientific expertise is seen in the early work of the physicists Hermann Helmholtz and Ernst Mach - they were so steeped in the music world that they believed sound and music to be interchangeable (Hui 2011; Hui 2012b).

A generation later, Wilhelm Wundt's lab would perform a series of experiments in which subjects would first be instructed to listen to two different tones and were then asked to judge whether a third was in between the first two (Lorenz 1890; Wundt 1891). The rigor of these experiments was rooted in the volume of data collected (hundreds of thousands of judgments) not in the listening skills of 
the experimental subjects. This was in contrast to the early experiments of the gestalt psychologist-ethnomusicologist Carl Stumpf. His work on the psychology of tone sensation described his experimental subjects' Musikbewusstsein, music consciousness, or even music-infected consciousness, as a critically important skill for the study of sound sensation (Stumpf 1888, 1890, 1891).

Wundt and Stumpf actually got into a vicious debate about the role of musical expertise in the experimental study of sound sensation, which I have discussed elsewhere (Hui 2012a). I have argued that it reveals a new development in the laboratory: a right and wrong way of listening and further, the decreasing value and validity of the subjective, individual experience of sound. So while in the mid-nineteenth century, the ability to properly read, play, and above all hear music was necessary to properly do science; by the 1890s this assumption came under attack.

There were, of course, theories of listening that existed outside the walls of the laboratory. Perhaps the most dominant in the German-speaking world were the writings of the Viennese music critic, Eduard Hanslick. Though his 1854 treatise, Vom Musikalisch-Schönen, was primarily devoted to advancing his system of formalist musical aesthetics, he also included a discussion of listening typologies. The proper, true method of listening, according to Hanslick, was aesthetic listening, what he defined as the voluntary act of pure contemplation. Required to properly execute this pure contemplation was the musical expertise to recognize and analyze musical forms, the basis of Hanslick's formalism (Hanslick 1854/1957). This nineteenth-century formalist approach to listening was the correct way of listening, to be protected and celebrated. ${ }^{1}$

Interest in the psychophysical effects of music (as opposed to purely emotional effects) can also be traced back to the nineteenth century (Ziemer 2008). This interest can be loosely broken down into three forms. First, there was extensive concern with the dangerous physical effects of music on the body of the, usually female, performer (Jackson 2006; Kennaway 2010). These concerns were bound up with shifting values and behaviors of the rising middle class - piano ownership recently made possible with the industrialization of piano manufacture, faith in Kultur and belief that proper upbringing included competence on several musical instruments, etc. Efforts by physicians, musical instrument-makers, acousticians, and pedagogues to ameliorate the dangers of musical vibrations on the body of the performer took many forms, from prohibitions against too much performing to the development of new pedagogical techniques and devices. The body was trained, not simply to perform music better but to perform music more safely (Jackson 2006).

Several individuals raised the second, related concern of psychological effects of music brought on by improper listening technique. Again, Hanslick is a nice example. The aesthetic listener he described was contrasted with the pathological listener who experienced music in "a twilight-state awash in sounding nullity" 
(Hanslick 1854/1957: 90-91). Or, even worse, was the observant listener - the very lowest common denominator of the audience - who sought only abstract feeling and experienced music “as if chloroformed” (Hanslick 1854/1957: 90-91). The musical experience of the individual who listened according to the proper rules of musical analysis was unquestioned. As long as the listening technique was correct (employed Hanslick’s formalism), the sounds heard were legitimate. However, if the listener approached music incorrectly - listened wrong - the effects were akin to drug use, both psychological and physical.

Concerns with the physical and physiological dangers of music can be contrasted with the third form: benefits (beyond Bildungsbürger priorities of Kultur). For example, at the end of the nineteenth century, Leipzig economist Karl Bücher, elaborating on his earlier work on non-market (gift and exchange) economics, argued that music co-developed with labor. In his Arbeit und Rhythmus, Bücher located the origins of early agriculture and husbandry in animal-mimicking play (Bücher 1899). He explained that imitation of the sounds and movements of animals was centrally important in the "dances of primitive peoples", and, further, that "all regularly sustained activity finally takes on a rhythm form and becomes fused with music and song in an indivisible whole" (Bücher 1893: 27-28). In his Die Enstehung der Volkswirtschaft (Industrial Evolution), he found the disciplinary role of music to be critical for the development of cooperative labor, a necessary step towards industrialization.

Bücher believed the developmental step of concatenated labor aggregation, in which several workmen proceed together in such united tasks as meadow-mowing or tossing bricks, was achieved through the introduction of artificial means of marking tempo. He explained that "counting, singing, accompaniment of music" was the means by which simple, separate aggregation of labor became labor concatenation (Bücher 1893: 276). He cited examples of song employed in slave and gang labor from Cameroon to Sudan to China as well as the use of rhythm in "modern States" to maintain discipline in military exercises (Bücher 1893: 277). Music aided in both disciplining individual and coordinating multiple bodies. Rhythm, music and modern collaborative laboring practices, according to Bücher, developed in unison.

So, the status of musical expertise in listening, both in the laboratory and beyond, was being renegotiated at the end of the nineteenth century. On the one hand, the subjective, individual experience of sound was losing value for psychological research. And, correspondingly, so was musical skill. It belied a vulnerability to observation bias and was therefore a menace. On the other hand, in the concert halls and on the city streets, the individual listener - if he or she was the right kind of listener - was an increasingly valued creature. Implicit in the negotiations over the role of musical expertise in listening was that the correct form of listening would result in the ideal experience of sound. There was an assumption that music had mechanical potential, it could cause certain effects. The interest in 
the bodily effects, both negative and positive, both on individuals and masses was both a consequence and contribution to this belief. The subsequent efforts of psychologists to experimentally confirm the motor effects of music in turn provided psychologists, and later, music marketers, with the tools to cultivate an entirely new kind of listening in relation to the introduction of new kinds of sound.

\section{Walter Bingham's Studies of the Motor Effects of Music}

Walter van Dyke Bingham is perhaps best known for his work during WWI as executive secretary of the Committee for Classification of Personnel in the Army for the War Department, essentially developing the intelligence and personality tests employed to rank and assign enlisted men and recruits; the first of several generations of aptitude tests that are still all the rage in America. He was trained in the psychology laboratories of Hugo Münsterberg at Harvard and James Angell at the University of Chicago. In 1915 Bingham founded and became director of the Division of Applied Psychology at the Carnegie Institute of Technology. Bingham stands at the intersection of scientific management and the mobilization of standardized mood effects of music, fully realized with the introduction of piped-in music to factories and workplaces in the 1930s.

In 1910 Bingham published "Studies in Melody," based on research done in the psychology labs of the University of Chicago and Harvard University, between 1905 and 1908 (Bingham 1910). The guiding question of Bingham's research was: What is melody? And if melody was a sense of unity (which he thought it was), how is this sense of unity perceived? Some previous experiments by others had suggested a relationship between the interpretation of the tonality phenomenon and kinaesthetic elements, motor accompaniments, sensations of strain and muscular movement (Meyer 1900; Lipps 1902; Meyer 1904; Weinmann 1904; Lipps 1905). So he set out to explore the motor effects of simple melodic stimuli.

Bingham's three-part hypothesis consisted of the following: First, attention was an activity that drew upon both special and general motor adjustments. Related, the general motor adjustments affect general body conditions. As a consequence, the rate of a circular motor process like finger-tapping, "which is going forward semi-automatically, will be affected by these activities, a decrease in rate signifying inhibition, due to increased activity elsewhere, and an acceleration signifying that the task of attention in organizing these activities is being successfully carried out” (Bingham 1910: 60).

To measure this decrease in rate signifying inhibition and acceleration signifying attention was being paid, Bingham relied on both the introspective testimony of the experimental subjects and precision measurements of rates of finger tapping. For this latter task, he developed a device for measuring finger-tapping rates, seen in figure 1. Experimental subjects were instructed to tap their fingers 
while a variety of tonal sequences were played for them, some that were internally coherent (in terms of pitch) and some that were not, some that were short (just two tones) and some that were much longer. The subjects were also questioned about whether a tonal sequence sounded "incoherent," "incomplete," "final," etc (Bingham 1910: 61-79). Subjects were students or instructors from the Harvard psychological laboratory who varied in their musical abilities.

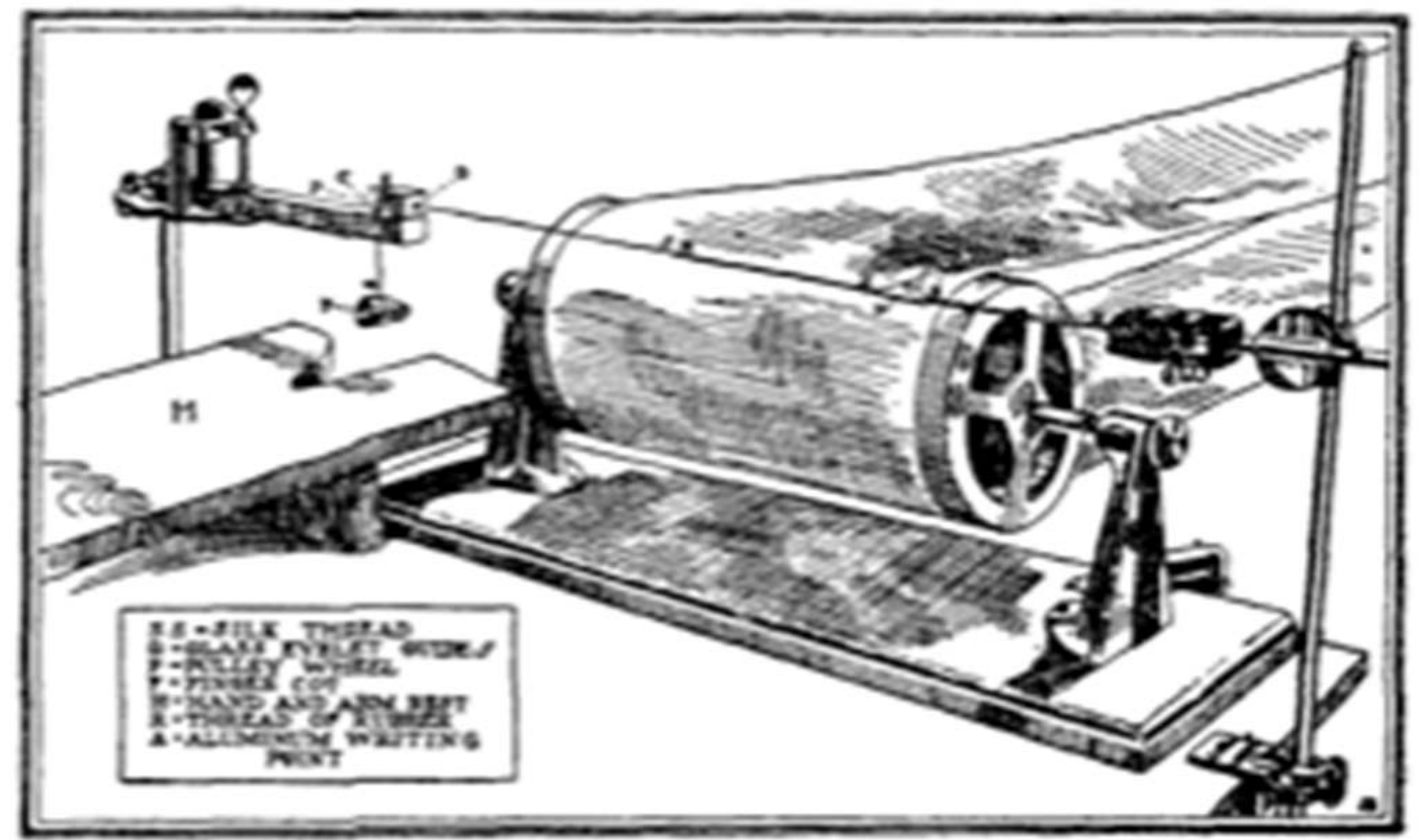

Figure 1. Device for measuring rate of finger tapping. W. V. Bingham, "Studies in Melody,” p.44

The introspection provided numerous interesting anecdotes. The experimental subject “Ta.," for example, tapped "with the regularity of a ruling engine” but could give no introspection report because the tones had no effect whatsoever (Bingham 1910: 72). Combined with tables of tapping rates, the introspective reports hinted at what elements constituted melody. A comparison of just the rates of the tapping, between melody and non-melody, was even more illuminating (see figure 2). Bingham's results were not conclusive but they were suggestive. The researchers did find a correlation between rates of tapping for the internal coherence and finality of tone sequences. 


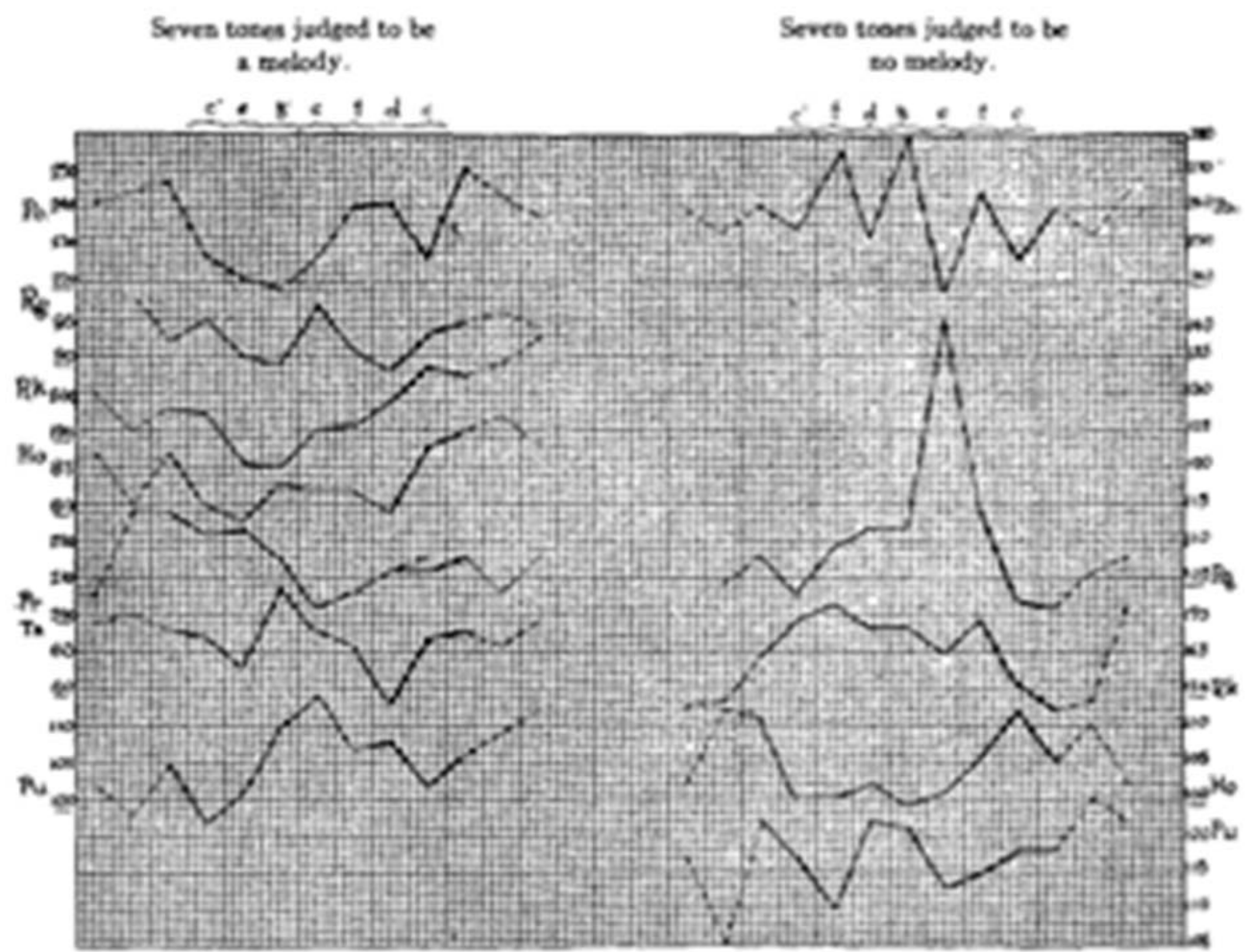

Fictze No. 3. Errects of a Meloox And a Nos-Meloox Contrasted. Each toce sounded for three seconds. Graphs represeat rate of tapping during eacb of these three-second periods. Note general tendescy toward increase in rate at close of melody, and absence of such accelerstioe at close of son-melodic sequence.

Figure 2. A comparison of the rates of finger tapping for melodic and non-melodic tonal sequences. W. V. Bingham, “Studies in Melody,” p. 79.

Bingham concluded that unity, which distinguished a melody from a mere succession of tones, did not arise from the tones themselves, but rather "it is contributed by the act of the listener." When the tones followed "in such a manner that the hearer can react adequately to each," they are "felt” as related. Then, Bingham explained, when the tonal series ends in such a fashion that the continuous reaction of the hearer is also completed, "the balanced muscular 'resolution' gives rise to the feeling of finality, and the series is recognized as a unity, a whole, a melody" (Bingham 1910: 87-88). So, as a melody was sounded, a parallel muscular response occurred. As the melody resolved, so did the muscular response. This resolution of the muscular response led to the recognition of the tone series as a melody. The muscular response mediated between the sounded tones and the experience of musical melody. It should be noted that at its core this was an aesthetic question, which Bingham in turn sought to answer through a measurement of motor response. He found a correlation between musical melody and motor mechanism. Musical melody could affect the movement of the body but not be recognized as such until after the fact. 
A testament to the growth in scholarly interest in the bodily effects of music as well as Bingham's leadership in the field, Bingham authored the introduction to an edited collection, The Effects of Music (1927). The collection was a compilation of several of the submissions to a 1921 essay contest sponsored by the American Psychological Association asking for an exploration of the effects of music. ${ }^{2}$ Thomas Edison had supplied the $\$ 500$ prize. The studies ranged from music's effects on mood to blood pressure to digestion as well as the effects of sequencing and selection of music programming. Bingham explained that the goal of the book was to both respond to the thoughtful listener's inquiry, "What is this music doing to me?" and a challenge to science to more adequately explain the "nature and mysteries of musical effects” (Bingham 1927/2001: 1).

The complexity of the variables affecting the musical experience was compounded by the personal background and training of the listener, he explained, confounding scientific study of music. Even isolating the two major determiners of music experience to the musical selection and listener, the listener in particular is impossible to generalize, varying in age, education, training, personality, talent and musical ear (Bingham 1927/2001: 2-3). A single piece of music could have widely varying effects. Bingham presented the example of an individual whose work on a hand-loom was steady and rapid while listening to jazz. Another worker became so agitated and distracted by the same piece that she exerted too much pressure on the apparatus that she had to concentrate more in order to avoid errors; she accomplished less than if she hadn't been subjected to music at all (Bingham 1927/2001: 3).

Bingham suggested that this example underscored the finding of his earlier experiments on the motor effects of melody, explaining that, "every listener who is at all musical, everyone to whom the succession of tones means anything, responds by exhibiting very slight but characteristic changes of muscular tonicity” (Bingham 1927/2001: 6). Further, he asserted, it was the listener, in responding to successive tones and binding them together, perceiving them as a unity, that created the melody. It was thus imperative to better combine the efforts of experimental psychologists and musical aesthetics to better understand the individual listener's experience of music. I want to emphasize this point: the leaders of this line of study believed that individual responses to music varied widely and were barely comprehensible despite the combined efforts of several disciplines to document musical effects with scientific precision.

\section{Tone Tests and Re-Creation Recitals}

I highlight this last point to underscore the ambitious nature of the Edison Company's program of what they termed demonstration recitals or tone tests. Launched in 1914, the Tone Tests and Re-Creation Recitals were an almost entirely Edison Company phenomenon, in part a product of Edison's anxiety about 
accusations of charlatanry rooted in his early years as an inventor in a late nineteenth-century American landscape replete with professional swindlers and carpetbaggers (DeGraaf, Archivist, Thomas Edison National Historic Park, personal communication, November 8, 2011). Instead, Edison wanted consumers to embrace his phonograph and cylinders because of their superior sound quality and the Tone Tests and Re-Creation Recitals were an opportunity for the public to experience the superiority of the Edison machine over others. It was also an opportunity for consumers to learn how to properly operate the device to generate a unified product. Further, I argue, the demonstration recitals were a means of training the disparate listeners Bingham studied to receive the phonograph's sound in a very specific way.

Demonstrators, supervised by the Phonograph Division of the Edison Company, would be dispatched to organize Tone Tests in cooperation with local Edison distributors and shops. The recitals would take place in stores that sold Edison products, churches, schools, YMCAs, and private homes. One was held on a Lake Erie ferry. The audiences ranged in size from a dozen to as many as 150 people. Usually the demonstrators initiated the Tone Tests but at times they would be requested for example in the case that a school district was interested in purchasing a phonograph for the district. This sometimes led to friction between the demonstrators and the local distributors. Distributors complained that the demonstrators would sweep into town and, unaware of local mores, would plan recitals in the wrong part of town or among the wrong kind of people and in the process alienate actual prospective buyers (Maxwell, personal communication, April 24, 1915). ${ }^{3}$

The Tone Tests were supposed to approximate a proper concert so the demonstrators weren't allowed explicitly advertise or promote the purchase of the Edison machine at the recitals (Maxwell, Internal Phonograph Division Bulletin, April 1, 1914; Maxwell, personal communication, April 17, 24, and 30, 1915). Sometimes lectures on music history by an academic or a music critic would be included. ${ }^{4}$ Programs listing the pieces to be performed by the phonograph were distributed. The audience applauded between pieces. The demonstrators would follow up with attendees and also report back to the Edison Company on the location and size of the Tone Test, the pieces performed, and a few sentences summarizing the audience reaction. These reports were initially just handwritten letters but were later standardized with an official form (Maxwell, reports and personal communication, April 21, 22, and 26, 1915, Amy 4, 5, and 16, 1915, and June 6, 21, and 23, 1915).

The Edison Company eventually caved to consumer pressure and began signing well-known performers to make recordings. These recording artists were then recruited to participate in the Tone Tests. These Re-creation Recitals juxtaposed the live performer against the recording of his or her voice (see figure 3). The recording artist would sing a duet with the phonograph, and then he or she would stop and allow the phonograph to perform solo. Sometimes, in an act of generosi- 
ty, the phonograph would go silent, and the recording artist would be allowed to perform solo. Sometimes the lights were switched off so that audiences couldn't tell whether machine or human were singing (this usually brought the house down). Audiences appeared to appreciate the additional human element offered by the re-creation recitals. One respondent noted that she liked when the recording artist gestured to the phonograph, humanizing the machine (W. Maxwell, personal communication, June 21, 1915).

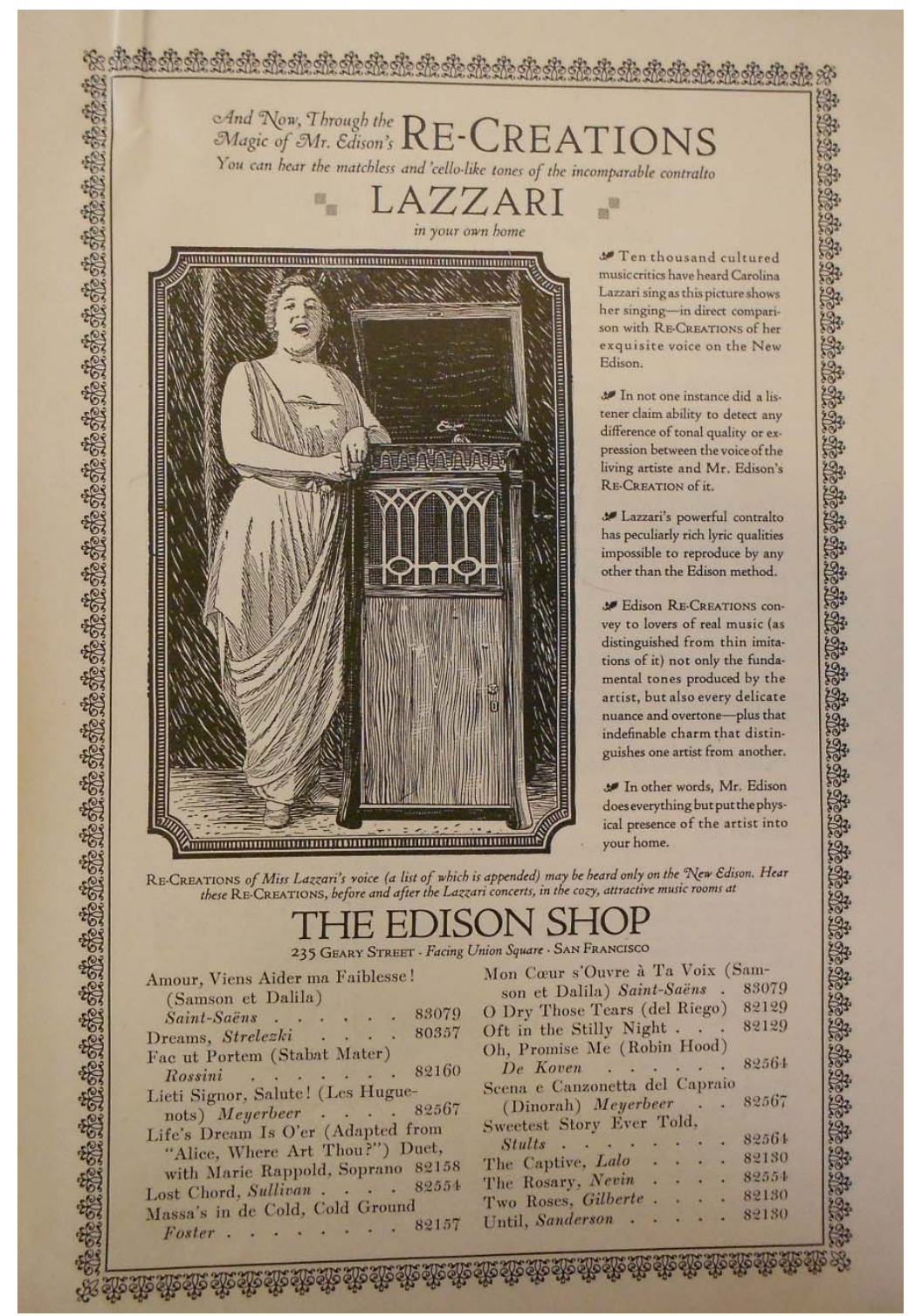

Figure 3. Promotional material for a Re-Creation Recital, Box 18, William Maxwell Files, Edison Historic Site Archives. 
The goal of these Re-creation Recitals remained to showcase the fidelity of the Edison instrument's sound. The recording artists were therefore encouraged to conform their voices to match the sounds generated by the phonograph (Thompson 1995; Milner 2007). Certainly they were forbidden from "showing up" the phonograph recording of themselves with the bending of notes or additional musical flourishes or simply singing louder. Advertising copy (see figure 4) declared, “The Artist's Tone is the Edison Tone," perhaps more revealing of the machinations of the Re-Creation Recitals than the marketing unit intended.

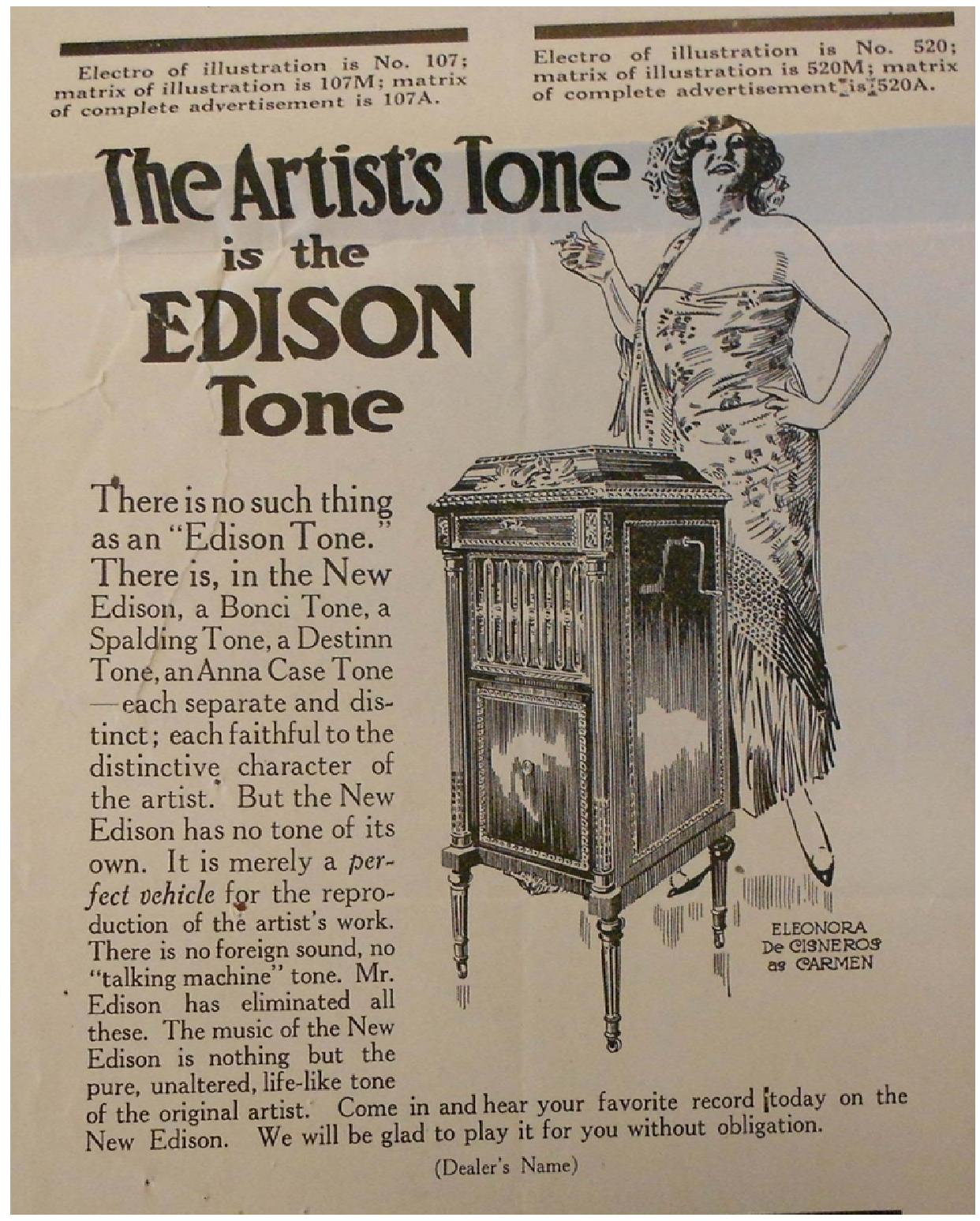

Figure 4. Advertising copy developed by the Edison Company, distributed to shop owners for purchase, Box 2, William Maxwell Files, Edison Historic Site Archives. 
Aiming to illustrate this equivalence of the artist's and phonograph's tone, the demonstrators would instruct the audience before, during, and after (in follow-up letters) the concert on what to listen for, sometimes to the point of irritating audience members. ${ }^{5}$ They emphasized the fidelity and clarity of the phonograph's tone and, unsurprisingly, deemphasized the scratching and buzzing sounds of the instrument. The demonstrators did not discuss the music itself. They did not discuss the formal structures of the pieces, nor the chord progressions, nor the interesting melodic elements. They were not training aesthetic listeners. Instead, the ReCreation Recitals functioned to highlight good sounds to the point that they sonically eclipsed bad ones.

This was not musical expertise. The phonograph did not make its listeners more musical. Nor did the phonograph communicate the pre-existing musical sophistication of its owners, if they had any. This is not to say, however, that the Tone Tests and Re-creation Recitals did not cultivate an expertise of sorts. The audiences were taught to be experts on sound fidelity. Further, they were trained to be experts at a new kind of listening. They could separate music from noise and to ignore, possibly not even hear, the latter. The Tone Test and Re-Creation Recitals functioned, through centralized and systematized demonstration protocol, to standardize both the sound object and listening experience.

\section{Mood Change Tests}

In 1921, under Bingham's leadership, the Edison Phonograph Division mailed out thousands of surveys, asking individuals to list the music they associated with certain emotions or moods. From the responses, Bingham developed the Mood Change Test. The Mood Change Test consisted of filling out part of the Mood Change Chart (see figure 5), listening to various music pieces, and then completing the chart.

Hoping to increase the sample size of the project, the Edison Company encouraged the public to visit an Edison shop to take a Mood Change Test and/or host "Mood Change Parties" in their private homes. Completed charts could be mailed in the Music Research Department of the Edison Laboratories. At least one Edison shop owner institut-

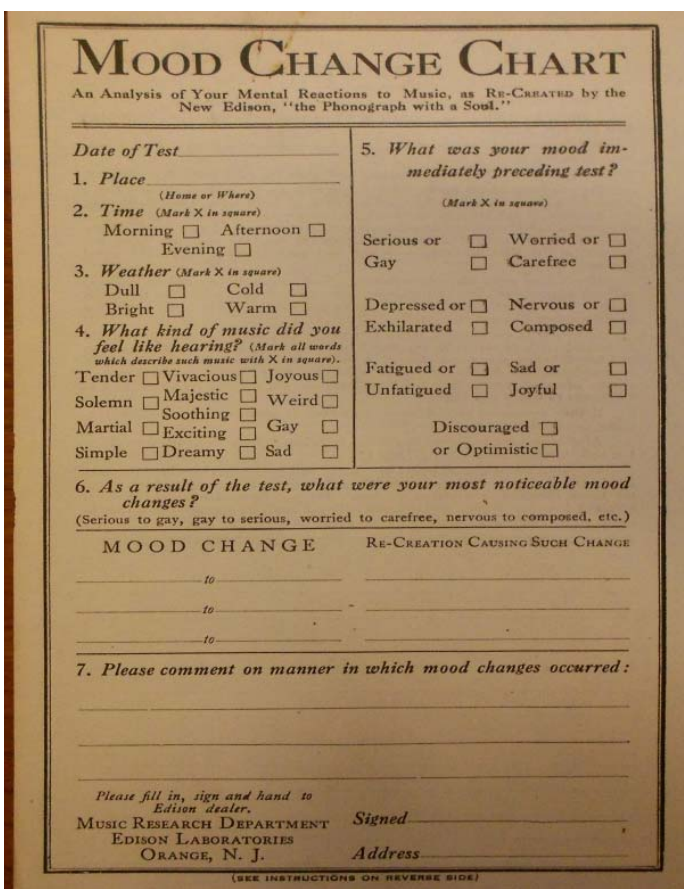

Figure 5. Mood Change Chart, Box 18, William Maxwell Files, Edison Historic Site Archives. 
ed the Mood Change Test as part of the application process for positions at the store (Maxwell, personal communication, April 9, 1921). Beginning in the Spring of 1921, in perhaps one of the earliest instances of the now time-worn tradition of using undergraduate students in introductory psychology courses for large scale studies, Mood Change Parties were performed on college campuses. These campuses included universities in the local West Orange, New Jersey area as well as Harvard and Yale (Maxwell, personal communication, March through May, 1921). There was also some discussion of combining Mood Change Parties with a show of large oil paintings at the Chicago Academy of Fine Arts.

Advertisements promoted the Mood Change Tests as sophisticated and groundbreaking science. A 1921 print advertisement that ran in Colliers, Lady Home Journal, and Cosmopolitan featured celebrity Private Investigator William Burns beside an Edison Phonograph and an enlarged copy of his completed Mood Change Chart. The copy below read: "It registers a decided mood change but it represents the emotional effects of music only on one man. Mr. Edison needs thousands of these charts because his research work must be conducted as the law of averages” (Maxwell, personal communication, November 22, 1920).

Demonstrators were deputized into the grand experiment. Internal communication from William Maxwell, the President of the Phonograph Division of the Edison Company, explained that the Mood Change Charts were part of "one of the most interesting experiments ever made in the world of music" and encouraged them to assist Bingham and Edison in "THIS NOVEL AND EPOCH-MAKING EXPERIMENT” (Maxwell, personal communication, January 12, 1921). Later, in response to a request for guidance on what music should be used at Mood Change Parties, Maxwell noted, "These Mood Change parties represent real research work. We are not attempting to confirm what we think. We are endeavoring to learn something new” (Maxwell, personal communication, February 22, 1921).

Maxwell anticipated that they would eventually collect thousands, possibly even hundreds of thousands of completed Mood Change Charts (Maxwell, personal communication, February 22, 1921). Certainly the charts provided extensive data for Bingham's studies on the mood effects of music. They also resulted in The Golden Treasury of Music, essentially compilation lists, ordered according to mood. These moods were descriptive, such as "physically stimulating," "emotionally stirring," "tenderness," "imagination's fancy." Below the mood was a list of five to twenty selections from the Edison collection of recordings along with their casting mold number, usually a mix of popular pieces and repertoirey ones.

Bingham's work on the motor and mood effects of music was made marketable. Also, such lists indicate a new approach to the listening process. Previous phonograph-listening practices consisted of choosing a specific piece or performer. The listening experience would unfold from that choice. The Golden Treasury of Music instead encouraged the listener to reverse this process and anticipate their desired mood first, to think of the listening experience in terms of their de- 
sired mood change - Want to feel tenderness? Choose from the list below! The specific piece or performer becomes unimportant.

We can understand this process as training the public to approach their musiclistening experience in an entirely new way and, as a consequence to listen in a new way as well. In the Spring of 1921 Maxwell received a letter from an enthusiastic Mood Change Test taker that complimented the Edison Company on their project, explaining that he believed the Mood Change Tests will teach the children of "regular American laborers" to play music and sing music. Forwarding this letter to Edison, Maxwell noted "If everybody gets this angle, we shall have the world by the tail." Edison replied, "I think many will” (Maxwell, personal communication, February 18, 1921). The subjective experience of listening to music made measurable and objectified by psychologists had become manipulable, and marketable. Sound objects became sound products.

\section{Conclusion}

The introduction of a uniform, material sound object that could penetrate into new spaces of listeners' lives contributed to new listening practices. Long term, we see the development of ever more sound objects, sound products - elevator music, background music, microbranding, and playful reactions by contemporary composers like Brian Eno or Robert Rich to these products. The phonograph provided a means of standardization and normalization not previously possible in music halls or laboratories. The rise of the phonograph - rather paradoxically since it was more mobile and accessible to individuals - created the possibility for a new experience of sound designed for the lowest common denominator of mass listening. Psychologists like Bingham furthered this, fueling new non-listening practices.

The measurement and subsequent standardization of listening practices resulted in an entirely new kind of listening, one in which the listener heard less. Though this development was certainly a gradual one, the Re-creation Recitals fittingly capture the separation of the listener from a direct experience of the generation of music. Audiences would experience the violinist struggle to eliminate the scratching sounds of her bow or the vocalist serenely hit a high, clear note. Then the wooden box would sound. They were standing there next to each other, deliberately coordinated in their performances, then uncoordinated. Again, the demonstrators emphasized fidelity of tone, not the quality of the composition or performance. The artist's tone and the Edison tone were one and the same.

Once bodily and mood reactions to music became measurable both psychologists and purveyors of mass-market technology sought to locate and mobilize this knowledge. The form of listening at the threshold of consciousness - threshold listening - was achieved through the objectification of subjectivity. Many music historians and musicologists have written about the social and cultural policing of 
listening behavior (Weber 1975; Johnson 1995). In this case, music itself (in new and specific contexts) functioned to make people behave a certain way - which, if its role was entirely functional, raises the question of whether it is even music at all. And if it is not music then what is it?

Alexandra Hui received her $\mathrm{PhD}$ in History at the University of California, Los Angeles. She is currently an Assistant Professor of History at Mississippi State University. She has published a monograph, The Psychophysical Ear: Musical Experiments, Experimental Sounds, 1840-1910 (MIT Press, 2012) as well as several articles on the relationship between psychophysical studies of sound sensation and music culture. She is also a co-editor and contributor to the 2013 Osiris volume on music, sound, and the laboratory.

\section{Notes}

1 Johannes Brahms is another example. Brahms was troubled by the lack of rigor in musical education and training in younger generations that listened to music without generating it. He instead emphasized a "proper” listening rooted in an ability to play. Brahms preferred an audience full of listeners who could experience his musical performances as if they were playing the music themselves (Botstein 1990).

2 The winner was the experimental psychologist Margaret Washburn of Vassar College. Washburn had examined the role of repetition of musical pieces on their perceived pleasantness or unpleasantness. Bingham, along with Harry Porter Weld of Cornell University and Harry Dexter Kitson of Columbia University, were judges.

3 All William Maxwell personal communications, bulletins, and reports are located in the William Maxwell Files at the Edison Historic Site Archives.

4 A Frank Hildebrand, for example, gave a series of Lecture-Recitals with such titles as "The Growth of Music", "Music and Life," and "The Opera” in 1915. Programs held in William Maxwell Files, Edison Historic Site Archives, Thomas Edison National Historic Park.

5 "Mrs. Rouland also said that she didn't like very much the idea of Mr. Fuller [the demonstrator] acting as though the audience knew nothing whatsoever about music, and had to be told every point to look for in the records.... Mrs. Edison's [likely no relation to Thomas Edison] chief objection was that the whole thing seemed to be more mechanical than artistic. The machine was too much in evidence and the artistic part too much in the background. She thought Mr. Fuller's efforts to be funny did not get over very successfully.” Maxwell, personal communication, June 21, 1915, William Maxwell Files, Edison Historic Site Archives, Thomas Edison National Historic Park.

6 Box 18, William Maxwell Files, Edison Historic Site Archives. 


\section{References}

Bingham, Walter (1910): “Studies in Melody”, The Psychological Review: Monograph Supplements, 12:3.

- (1927/2001): “Introduction”, Max Schoen (ed.): The Effects of Music: A Series of Essays, edited by Max Schoen, London: Kegan Paul, Trench, Trubner \& Co, 1-9. Reprinted by Routledge in 1999 and 2001.

Bjisterveld, Karin (2008): Mechanical Sound: Technology, Culture, and Public Problems of Noise in the Twentieth Century, Cambridge, MA.: The MIT Press.

Botstein, Leon (1990): “Time and Memory: Concert Life, Science, and Music in Brahms's Vienna”, Walter Frisch (ed.), Brahms and his World, Princeton, New Jersey: Princeton University Press.

Bücher, Karl (1899): Arbeit und Rhythmus, Leipzig: Teubner.

- (1893/1907): Industrial Evolution, translated from $3^{\text {rd }}$ German edition by S. Morely Wickett, New York: Henry Holt and Company.

Hanslick, Eduard (1854/1957) The Beautiful in Music, edited by Morris Weitz and translated from the $7^{\text {th }}$ German edition by Gustav Cohen, New York: Liberal Arts Press.

Hui, Alexandra (2011): “Instruments of Music, Instruments of Science: Hermann von Helmholtz's Sound Sensation Studies, his Classicism, and his Beethoven Sonata”, Annals of Science, 68:2, 149-177.

— (2012a): “The Bias of 'Music-Infected Consciousness': the Aesthetics of Listening in the Laboratory and on the City Streets of Fin-de-Siècle Berlin and Vienna”, Journal of the History of the Behavioral Sciences, 28:3, 236-250.

_ (2012b): The Psychophysical Ear: Musical Experiments, Experimental Sounds, 1840-1910, Cambridge, MA.: The MIT Press.

Jackson, Myles (2006): Harmonious Triads: Physicists, Musicians, and Instrument Makers in Nineteenth-Century Germany, Cambridge, MA.: The MIT Press.

Johnson, James (1995): Listening in Paris: a Cultural History, Berkeley: The University of California Press.

Kennaway, James (2010): "From Sensibility to Pathology: The Origins of the Idea of Nervous Music Around 1800”, Journal of the History of Medicine and Allied Sciences, 65, 396-426.

Lipps, Theodor (1902): “Zur Theorie der Melodie”, Zeitschrift für Psychologie und Physiologie der Sinnesorgane, 27, 225-263.

Lipps, Theodor (1905): Psychologische Studien, $2^{\text {nd }}$ ed. Leipzig: Verlag der Dürr'schen Buchhandlung.

Lorenz, Carl (1890): “Untersuchungen über die Auffassung von Tondistanzen”, Philosophische Studien, 6, 26-103.

Meyer, Max (1900): “Elements of a Psychological Theory of Melody,” Psychological Review, 7:3, 241-273.

(1904): “Unscientific Methods in Musical Esthetics”, Journal of Philosophy, Psychology and Scientific Methods, 1, 707-715.

Milner, Greg, (2007): Perfecting Sound Forever: An Aural History of Recorded Music, New York: Faber \& Faber.

Myers, Charles (1927): “Individual Differences in Listening to Music”, Max Schoen (ed.). The Effects of Music, New York: Routledge, 10-37.

Ortmann, Otto (1927): “Types of Listeners: Genetic Considerations”, Max Schoen (ed.): The Effects of Music, New York: Routledge, 38-77.

Pinch, Trevor \& Karin Bijsterveld, (2003): "Should One Applaud? Breaches and Boundaries in the Reception of New Technology in Music”, Technology and Culture, 22, 536-559.

Pinch, Trevor and Frank Trocco, (2002): Analog Days: The Invention and Impact of the Moog Synthesizer, Cambridge, MA.: Harvard University Press.

Schafer, R. Murray (1977/1994): The Tuning of the World: Toward a Theory of Soundscape Design, New York: Knopf. When reprinted in 1994, retitled to The Soundscape: Our Sonic Environment and the Tuning of the World. 
Sterne, Jonathan, (2003): The Audible Past: Cultural Origins of Sound Reproduction, Durham, North Carolina, Duke University Press.

Stumpf, Carl (1888): "W. Wundt, Grundzüge der physiologischen Psychologie; E. Luft, Über die Unterschiedsempfindlichkeit für Tonhöhern”, Vierteljahrsschrift für Musikwissenschaft, 4, 540550.

_ (1890): “Über Vergleichungen von Tondistanzen”, Zeitschrift für Psychologie und Physiologie der Sinneorgane, 1, 419-462.

- (1891): "Wundt's Antikritik", Zeitschrift für Psychologie und Physiologie der Sinnesorgane, 2, 266-293.

Thompson, Emily (1995): "Machines, Music, and the Quest for Fidelity: Marketing the Edison Phonograph, 1877-1925”, The Musical Quarterly, 29:1, 131-171.

(2002): The Soundscape of Modernity: Architectural Acoustics and the Culture of Listening in America, 1900-1933, Cambridge, MA.: The MIT Press.

Weber, William (1975): Music and the Middle Class: The Social Structure of Concert Life in London, Paris and Vienna, New York: Holmes and Meier Publishers.

Weinmann, Fritz (1904): “Zur Struktur der Melodie”, Zeitschrift für Psychologie und Physiologie der Sinnesorgane, 38, 238-239.

Wundt, Wilhelm (1891): “Ueber Vergleichungen von Tondistanzen”, Philosophische Studien, 6, 616-617.

Ziemer, Hansjakob (2008): Die Moderne hören: Das Konzert als urbanes Forum 1890-1940, Frankfurt/New York: Campus. 